\title{
PROGRESS AND CHALLENGES IN MONITORING OCEAN TEMPERATURE AND HEAT CONTENT
}

\author{
S. E. Wijffels ${ }^{(1)}$, M. Palmer ${ }^{(2)}$, N. Rayner $^{(2)}$, G. Goni ${ }^{(3)}$, S. Garzoli ${ }^{(3)}$, G.C. Johnson ${ }^{(4)}$, J. Willis ${ }^{(5)}$, B. Dushaw ${ }^{(6)}$, \\ D. Roemmich $^{(7)}$, J. Church $^{(1)}$, G. Meyers ${ }^{(1)}$

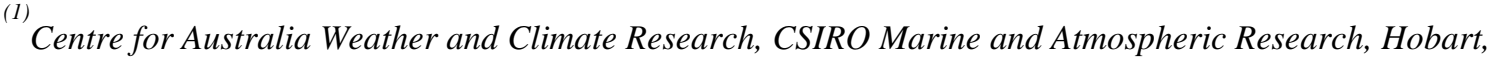 \\ Australia,Email: Susan.Wijffels@csiro.au, John.Church@csiro.au, Gary.Meyers@csiro.au \\ ${ }^{(2)}$ Met Office Hadley Centre, FitzRoy Road, Exeter, EXI 3PB, UK, Email: matthew.palmer@metoffice.gov.uk \\ (3) \\ National Oceanic and Atmospheric Administration, Atlantic Oceanographic and Meteorological \\ Laboratory, 4301 Rickenbacker Causeway, Miami, FL 33149, USA, Email: Gustavo.Goni@noaa.gov, \\ Silvia.Garzoli@noaa.gov \\ ${ }^{(4)}$ NOAA/Pacific Marine Environmental Laboratory 7600 Sand Point Way NE, Bldg. 3 Seattle WA 98115-6349, USA, \\ Email: Gregory.C.Johnson@noaa.gov \\ ${ }^{(5)}$ Jet Propulsion Laboratory, California Institute of Technology, M/S 300-323, 4800 Oak Grove Dr., Pasadena, \\ CA 91109, USA, Email: joshua.k.willis@jpl.nasa.gov \\ (6) Applied Physics Laboratory, University of Washington, 1013 N.E. 40th St., Seattle, WA 98105, USA. \\ Email: dushaw@apl.washington.edu \\ (7) Scripps Institution of Oceanography, University of California San Diego, 9500 Gilman Drive, La Jolla CA \\ 92093-0230 USA, Email: droemmich@ucsd.edu
}

\section{THE NEED}

As discussed by [1], the ocean observing system enables better understanding and prediction of weather, climate variability (seasonal through decadal) and climate trends, as well as information on the ocean state itself. These data and forecasts underpin many societal applications such as informing sustainable management of marine resources, farm management, disaster mitigation (oil spills, bush fire risk, drought, floods), planning and regulating long-lived infrastructure both on the coasts and inland (e.g. water supplies) and many more. Any future international mechanisms for mitigation of Greenhouse Gas emissions will require constant monitoring of the climate system response.

Temperature is the single most important ocean climate variable. Due to its vast thermal inertia, low albedo, high emissivity and dominance of the planetary surface area, the oceans play a key role in the planetary radiation balance, and thus are a strong control of planetary climate on timescales from weeks through to millennia.

Sea surface temperatures (SST) reflect and mediate energy exchange between the ocean and atmosphere. On short (weather) time scales, SST is a critical driver of atmospheric behaviour and an essential parameter for numerical weather prediction [2]. It is also being increasingly recognized that subsurface temperatures also control the growth potential of tropical storms, and thus more accurate predictions of extreme events such as hurricanes may require knowledge of upper ocean temperature field and not just SST [3] (Fig. 1).

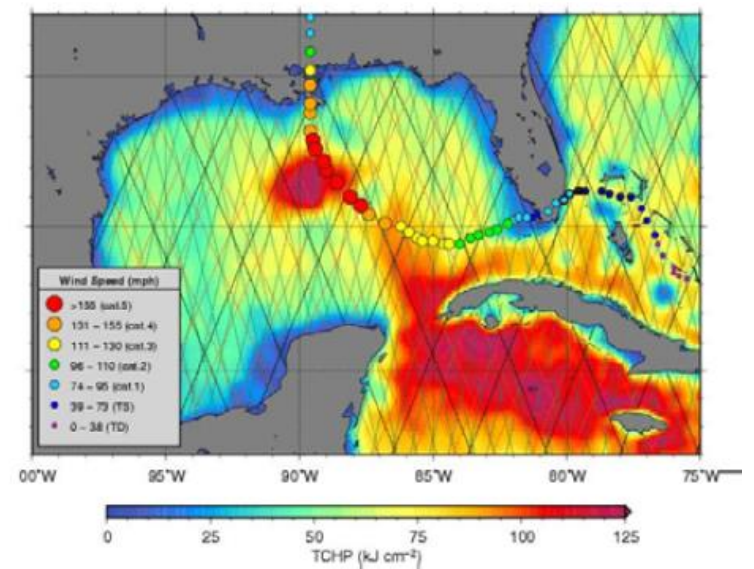

Figure 1. Tropical Cyclone Heat Potential (TCHP) field during Katrina obtained using data from JASON-1, GFO (GEOSAT (Geophysical/Geodetic Satellite) Follow-On) and ENVISAT (Environmental Satellite), with cyclone wind speeds overlaid. The groundtracks of the satellite from which observations are used to estimate the TCHP fields are superimposed (taken from [3])

Ocean temperature is also a strong factor in shaping marine ecosystems and their variability. Most marine creatures are highly sensitive to temperature changes, and many are adapted to live in only narrow temperature ranges [4]. Both short and longterm changes in ocean temperatures can impact on these ecosystems, and thus the distribution and abundance of global ocean productivity [5] and thus fisheries. Hence, tracking ocean temperature variability is a key 
requirement to better manage and sustain ocean food production and marine biodiversity.

The ocean's storage and transport of heat is a key control of the mean and seasonal climate across the Earth [6]. The oceans ability to absorb vast amounts of heat in one place and time, and release it back to the atmosphere in another place and time, combined with the comparatively small thermal inertia of the atmosphere, means that the distribution of heat in the oceans is the primary source of climate predictability. Upper ocean heat distribution is recognized as the principle data stream needed to initialize modern seasonal climate forecasting systems [7]. For climate prediction on decadal timescales, knowledge of the deep ocean heat distribution is needed [8 and 9] as over longer timescales, the ventilation of deep parts of the ocean becomes more important to energy flows. Thus the further out we want to reliably predict climate, the deeper we must measure the ocean.

On multidecadal timescales, the small but persistent planetary energy imbalance associated with the build-up of anthropogenic greenhouse gases in the atmosphere are dominantly stored in the ocean [10] - thus tracking the strength of the Greenhouse Effect, and any real progress society is making in slowing down planetary warming requires tracking global ocean heat content (GOHC). In addition, ocean thermal expansion drives around $30-50 \%$ of global sea level rise, and the distribution of heat in the ocean largely controls regional patterns of sea level [11]. How well we have achieved measuring GOHC in the past and to date is considered in detail below.

\section{THE CHALLENGES}

A common set of challenges are clearly identifiable across the science and operational community's efforts and aspirations to document ocean temperature variability. Many of these challenges apply to our efforts to measure other ocean variables, (such as salinity or oxygen concentration) which are generally more expensive to measure than temperature with fewer historical data. The first hurdle in any monitoring system is to have sensors that are low cost, very accurate and stable. For ocean temperature (but not entirely for pressure) this hurdle, at least, has been cleared. For many other ocean parameters, this core technical challenge remains in play.

The first challenge lies in sustaining and completing the existing core observational systems. Generally, the ocean remains highly under sampled nearly everywhere, due to both the technical difficulty of obtaining ocean observations, their expense and the rather small size of global community currently tasked with monitoring the ocean environment. While much progress has been made, key networks designed decades ago remain incomplete.
The next challenge is to fill the major gaps in the global ocean temperature observing system. A clear consensus emerges that these gaps include the climatically important and sensitive ice-covered oceans, the deep oceans and the marginal seas.

A third and long known challenge lies with reconstructing past ocean temperature changes from the instrumental record. With the need for more accurate predictions of future climate on decadal timescales becoming more urgent, historical data on the past planetary energy imbalance is needed to test and improve climate prediction systems. Our community, while making some progress, has much still to do in retrieving past data, quality controlling it and identifying and removing instrument biases.

A related challenge lies with transitioning some existing observations systems from ones focused on short term forecasting (for which they were designed and funded) to include the needs of climate monitoring and prediction. Here we face issues around accuracy, capturing meta-data and archiving.

\section{TRACKING THE PLANETARY HEAT BUDGET}

As the ocean comprises the single largest source of thermal inertia in the climate system, its changing heat content reflects the planetary energy imbalance at the top of the atmosphere [10]. Thus, the changing ocean heat content is a key measure of the opposing anthropogenic effects of reduced long wave loss due to increasing anthropogenic Greenhouse gases and the cooling associated with reflective aerosols and their effects on clouds. Understanding and being able to predict the future energy balance is essential for both guiding societal mitigation and adaptation to climate change. So, how well do we know the history of global ocean heat content (GOHC)? This apparently simple metric turns out to be rather challenging to track and provides a good illustration of some of the key issues facing the global ocean observing system. In [12] details are provided around the issues discussed below.

Due to very limited historical sampling below $850 \mathrm{~m}$, an observationally-based time history of GOHC can only be constructed for the upper $\sim 700 \mathrm{~m}$ (or 20\%) of the ocean volume. Current estimates of past upper ocean GOHC differ greatly from those made 5 years ago (Fig. 2), largely due to the discovery and correction of biases in the measurements from expendable BathyThermographs (XBTs), first documented in [14]. XBT data dominate the ocean thermal data archive between 1970 and 2002 after which the Argo (Global array of free-drifting profiling floats) Programme [15] data flow dominates. Several correction techniques for XBT data have been proposed, though there remains a lack of consensus on whether the errors arise from temperature and/or depth biases. Confounding these 
efforts are a lack of meta-data available for past historical temperature data - XBT data acquisition systems have evolved from analogue to digital, and the probe types and probe fall rates applied have also changed. Much of this information was not captured or is inaccurate in the current ocean archives. This underscores the importance of technical meta-data to the climate record, and the need to intensify data archaeology projects, which aim to retrieve both data and meta-data from original records.
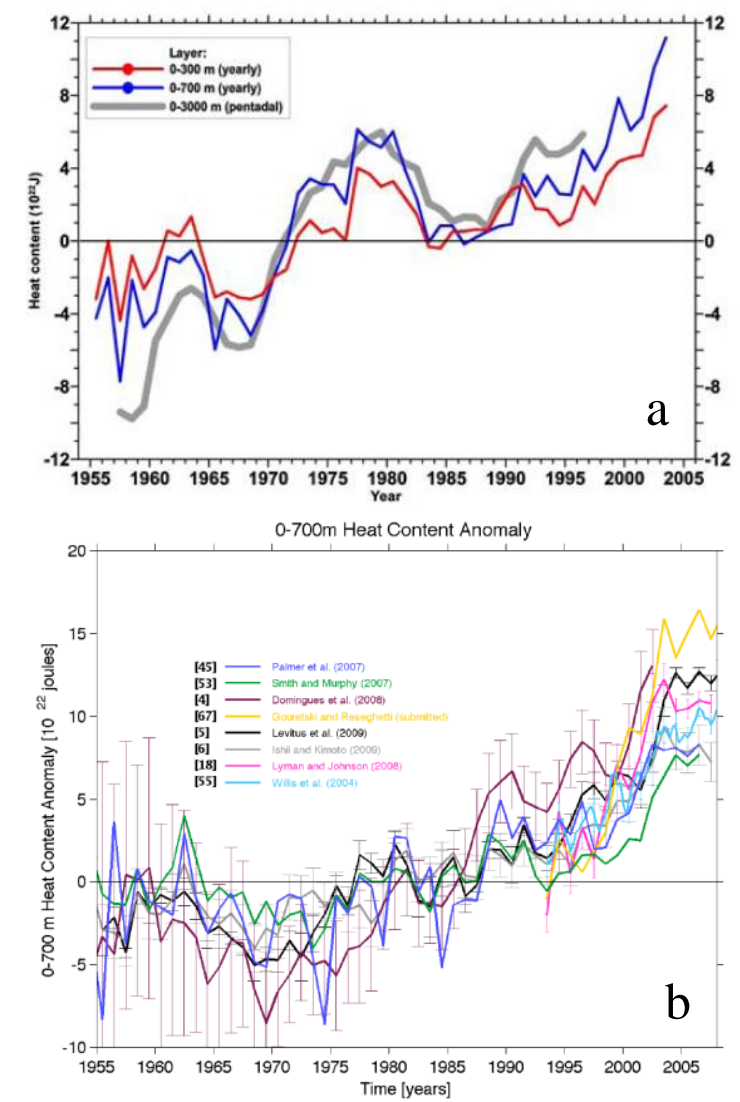

Figure 2: Observation-based estimates of annual ocean heat content anomaly $\left(10^{22} \mathrm{~J}\right)$ - a) Time history estimated before biases in XBTs were recognized [13]; b) More recent estimates compiled by [12]. Anomalies are computed relative to the 1955-2002 average. The blue curve in a) is directly comparable to the estimates in $b$ ).

Despite the various approaches to XBT bias corrections, the resulting updated estimates of GOHC history are beginning to converge somewhat (Fig. 2b). However, at both sub-pentadal timescales and for the multidecadal trend, the spread is still fairly high. It is believed that these differences come from varying approaches to filling data voids (method bias) and the efficacy of the averaging/gridding procedures in reducing the primary source of noise, the unresolved ocean eddy field (sampling error). Lyman and Johnson [16] quantify this sampling error for each past year by using the modern satellite altimetric record to model the eddy noise in GOHC in past years (Fig. 3). The steady reduction in sampling error as the ocean observing coverage grows is evident, with a clear drop in error when XBT's became widely deployed in the late 1960's and then again in 2002 with the ramp up of the Argo Programme. The impact of the method bias associated with gap filling is also evident in Fig. 3 where the "no data, no signal" bias that results from assuming an initial guess of zero anomaly for optimal averaging produces an error of twice that when gaps are filled using the global spatial average. It is also noteworthy that sampling and method bias error for both gap-filling assumptions converge with the full implementation of Argo by late 2007 [15], reducing the error in GOHC to $0.510^{22} \mathrm{~J}$, which compares with the next largest store of heat in the global climate system over the past 50 years - warming of the continents $-0.910^{22} \mathrm{~J}[13]$.

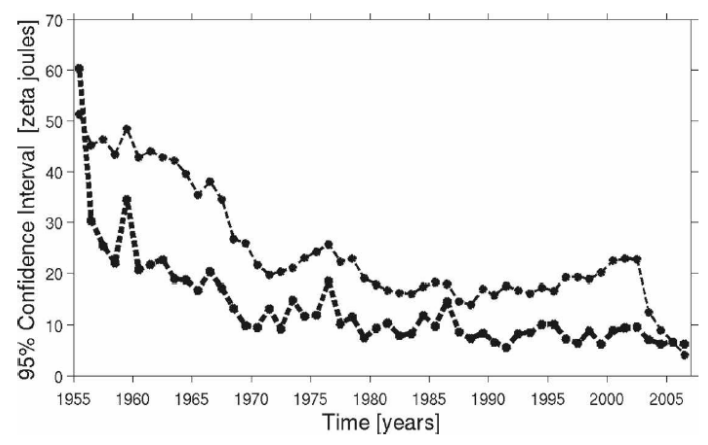

Figure 3: Sampling error for past years data coverage based on an optimal averaging from synthetic estimates of globally integrated OHCA $\left(10^{21} \mathrm{~J}\right)$ for two approaches to gap filling: thin dashed line- assumes a zero initial guess which is common to most optimal averaging schemes and the thick dashed line is for the assumption that the global mean signal occurs in the data poor regions [taken from 16].

Despite the recent progress in driving down the sampling error and method bias error via the nearcomplete implementation of Argo (Array for Real-time Geostrophic Oceanography), instrument biases remain a salient issue - not due to thermistor accuracy limitations (stable to $0.005^{\circ} \mathrm{C}$ on modern CTDs (ConductivityTemperature-Depth) used on Argo floats), but due to the accuracy of the measurement of pressure. While the Argo data community is working through these issues (and is able to make progress due to the programme's meticulous archiving of technical meta data, such as sensor serial number), improvements in pressure sensor stability are required in order to further reduce bias errors in GOHC estimates.

A remaining source of error in historical data yet to be discussed is poor quality-control (QC) of historical data 

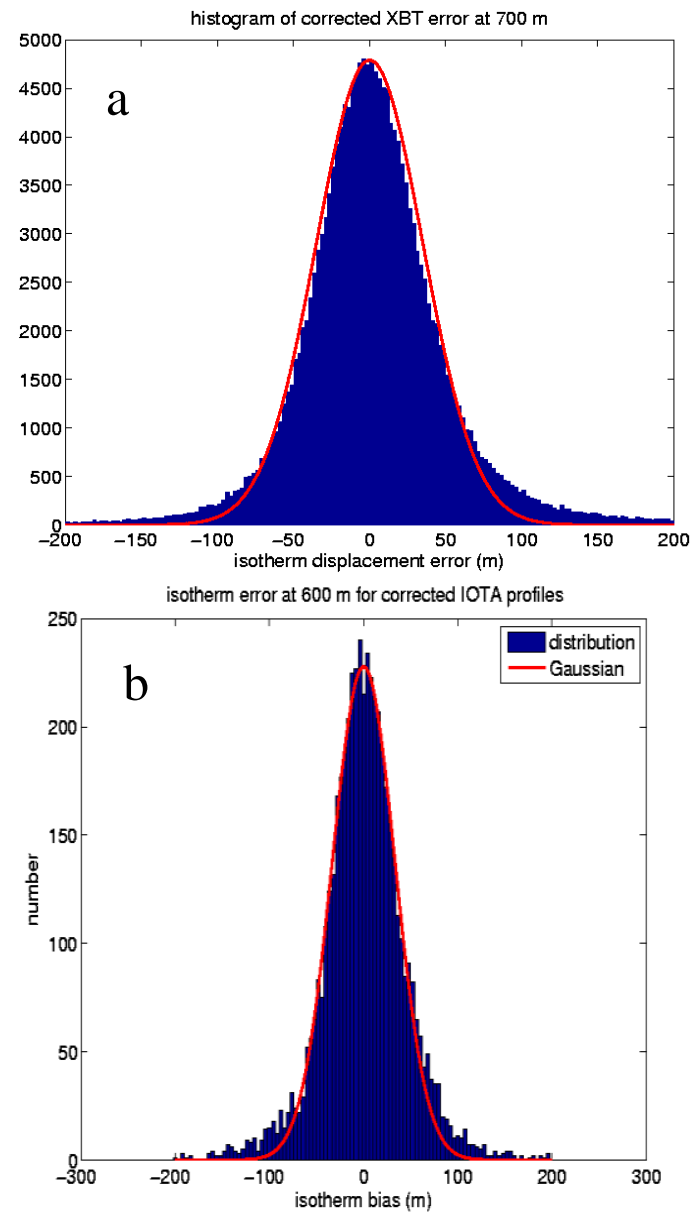

Figure 4: A histogram of depth errors for XBTs estimated from the pseudo-profile method based on satellite altimetric data as described in [17]: a) for profiles from the World Ocean Data Base and the Global Temperature and Salinity Profile Program and b) from the expert quality controlled QuOTA archive [18]. Red curves show a symmetric Gaussian curve fit to the data. Note the positive tail in a), indicating warm biases in the XBT profile data. Source: Josh Willis and Ann Thresher, personal communication, 2009.

archives. The removal of spikes and data affected by instrument failure requires expert examination of the data, which is expensive. To date automated tests have not been successful at screening out bad data without rejecting a lot of good data. For the problem of estimating GOHC, it might seem plausible that the massive averaging required to form the global integral would reduce these undetected instrument errors. However, for the historically dominate XBT data it is known that many common equipment failure modes (such as an insulation penetration on the conductive wire) produces warm-biased data. This effect can be detected for the satellite altimetric period by comparing deduced depth errors in profile archives that have undergone different QC (quality control) treatments (Fig. 4). The archive that has undergone expert screening produces the expected symmetric error distribution (Fig. 4b), while the archive that has been automatically QC'd shows a warm tail in the depth error (Fig. 4a), reflecting undetected instrument errors. Thus, archives not expertly QC'd will feature an overall warm bias.

Finally, we return to the fact that until the implementation of Argo, repeated broadscale temperature measurements were largely confined above $800 \mathrm{~m}$ - the deep ocean remains inadequately sampled and thus estimating its contribution to the time history of GOHC is nearly impossible.

Reconstructing the history of the GOHC thus touches on many of the challenges facing the observing system and efforts to build an accurate climate record. As, noted above, these issues form a central set across other key metrics required from the climate observing system.

\section{SUSTAINING AND COMPLETING CORE EXISTING SYSTEMS}

Progress over the last decade in the global ocean temperature observing system is detailed in the relevant white papers but includes

$\checkmark$ Near complete implementation of the core Argo mission with 2800 (out of a target of 3000) active floats delivering good data in the open and ice free oceans

$\checkmark$ Improvement in global distribution and number of surface drifters for SST

$\checkmark$ Continuous high precision satellite altimetry since 1992

$\checkmark$ Extension of the coverage of the tropical moored array into the Indian Ocean

$\checkmark$ The reinvigoration of the science of SST estimation based on the synthesis of the multiple satellite platform data streams and in situ data-producing new and better SST products (with errors) via the Global High Resolution SST project (GHR-SST).

$\checkmark$ The transition of the global XBT network from broad-scale monitoring (taken over by Argo) to circulation monitoring via frequently repeated (FRX) and high-resolution (HDX) lines with a global design.

$\checkmark$ The success in internationally coordinated efforts to reoccupy a subset of deep hydrographic and tracer sections sampled during the World Ocean Circulation Experiment (WOCE). This is the only data set delivering a global view of how the full depth ocean is changing, including its geochemical fields. 
In moving forward, the single most important goal is to complete and sustain these elements of the observing system, which complement each other with little redundancy. The Argo core mission goal is yet to be achieved, with float densities in the Southern Hemisphere gyres remaining below target [15]. The global surface drifter array remains skewed to the Northern Hemisphere and lower latitudes - uniform global density targets have not been achieved, restricting progress in the improving the accuracy of SST estimates in high latitude regions [2]. The global network of repeat XBT lines has demonstrated the community's adaptability by moving from targeting broadscale ocean temperature structure to monitoring circulation changes and boundary regions [19]. However, the implementation of the redesigned network of FRX (Frequently Repeated XBT) and HDX (High Density XBT) lines is not yet complete (often due to logistical challenges as well as funding limitations). Global repeat hydrographic observations are proving more and more valuable, as deep ocean and biogeochemical changes become apparent - this activity requires ongoing tight international coordination and support [20].

Satellite observations of both SST and surface sea level form an essential requirement, and in both cases we must sustain a multiple platform and sensor approach, and ensure adequate mission overlap to intercalibrate the sensors for a seamless climate record.

\section{THE MAJOR GAPS}

The present in situ ocean temperature observing system is largely confined to the ice-free open oceans above $2000 \mathrm{~m}$, with the limiting factors being observing system technologies (cost) and legal constraints. Prior to Argo, the ice-free polar oceans were poorly sampled and primarily in summer. The global surface drifter array remains at suboptimal densities in these regions, and satellite retrievals are difficult to process due to insufficient understanding of biases in the cold, high wind, high wave surface conditions.

The seasonal and fast ice zones present an even greater challenge for both in situ and satellite observing capabilities: they are currently excluded from the Argo core mission, ship-based sampling is largely confined to summer, surface drifters do not survive, and satellite data from a mixed ice/ocean field are hard to calibrate and process. However, due to technological progress (profiling floats that can operate and survive in ice zones, miniature CTDs that can be incorporated onto tags used to study and track apex predators) the community recognizes several clear opportunities to start to fill this major gap:

- Extend Argo to the seasonal ice zone [15] combined with an animals as platforms program [21]
- Complete the global surface drifter array with particular attention to high latitude oceans [2]

The ocean below $2000 \mathrm{~m}$ remains inadequately monitored [22]. Besides a small number of deep time series stations (largely restricted to the North Pacific and Atlantic Oceans), the global repeat hydrographic program [20] is the only broadscale deep ocean sampling achieved. While eddy-resolving along the transects, these sections are sparse in both space (one or two meridional or zonal transects per basin) and time (5-10 year repeat spacing). Despite their sparse coverage, these sections are revealing clear evidence of widespread near bottom ocean warming (Fig. 5),. which could be important for global energy and sea level budgets. However, extending these results to form a global integral remains difficult.

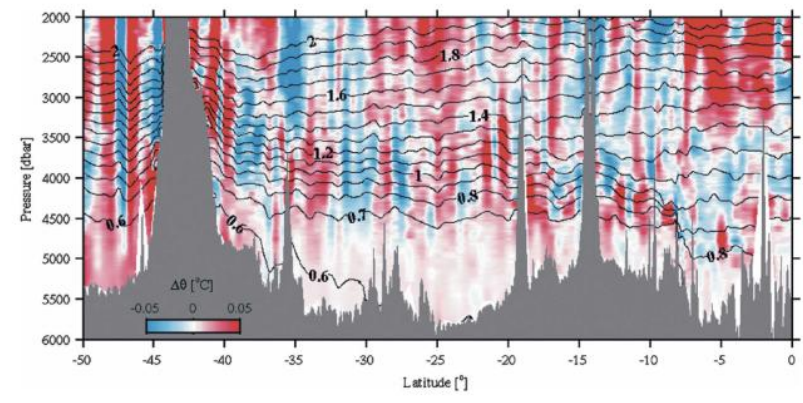

Figure 5: Sections of potential temperature difference $\left({ }^{\circ} \mathrm{C}\right)$ between 2001 and 1996 for a hydrographic section nominally along $170^{\circ} \mathrm{W}$, colour shaded as a function of latitude and pressure. (a) Red areas indicate warming and blue areas indicate cooling, with color saturation at $0.05^{\circ} \mathrm{C}$. Mean potential temperatures from all the data (black lines) are contoured (from [23]).

As discussed in detail by [22], broadscale observations of the abyssal ocean remain both a scientific (in terms of design) and technical challenge (platform and instrument developments are needed - such as deep sampling and reliable gliders or floats). Hence in the next decade a strategy needs to be developed to tackle this large and poorly sampled ocean volume:

- Continue to develop and pilot broad-scale deep ocean monitoring technologies to inform a global future strategy.

- Build an international strategy for deep ocean monitoring which will optimize the mix of platforms used such as deep moorings, repeat sections, deep profiling floats and gliders, and ocean acoustic thermometry [24].

We must also improve satellite SST products by continuing the work of GHRSST (Global High Resolution Sea Surface Temperature) and further developing the in situ sampling network to support the calibration and synthesis of satellite data streams [2]. 
One clear need is for global near surface high resolution profiles to help resolve and model very near surface temperature structures so skin (measured by satellites) and bulk temperatures can be better linked.

- Implement high-resolution near surface profiling on Argo for better calibration of satellite SST data.

Lastly, many of the existing networks do not operate in marginal seas. This is likely due to several factors, including their lesser importance for global climate, legal restrictions on the collection and dissemination of data from territorial waters, and heavy fishing activity which limits platform life. While some marginal seas are being instrumented through regional cooperative efforts, others remain unobserved.

- Target major marginal seas for the design and implementation of an observing system

\section{RECONSTRUCTING THE CLIMATE RECORD}

Data archaeology and quality controlling historical data are poorly funded activities. This is despite the fact that a high quality bias free ocean data archive is a prerequisite for reconstructing the past history of the ocean state. While the investment in testing, building and running ocean reanalysis/data assimilation machinery (with the required supercomputer infrastructure) continues to grow, a comparable growth in the investment in the assembly and QC of the feeder data sets is lacking.

The QC of historical archives requires expert manpower and is thus expensive, as is the discovery and digitisation of historical observations. Much progress has been made by the Global Oceanographic Data Archaeology and Rescue Projects (GODAR) [25]. The task of platform and data set cross-checking also requires a concerted effort, and is currently not well coordinated - many of these challenges are discussed by [26]. Thus we recommend

- Strengthening of data archaeology activities, including attempts to source original high resolution data with more meta-data

- more platform and system intecomparisons and syntheses e.g. comparison of near surface temperatures between marine meteorological data and ocean profile data; XBT vs Argo; etc

- both model (data assimilation) and statistical syntheses - historical and in near-real time to reveal platform inconsistencies and QC problems

\section{TRANSITIONING LEGACY SYSTEMS: DUAL USE FOR SHORT-TERM PREDICTION AND CLIMATE MONITORING}

Some of our in situ network and associated data distribution and management systems were designed and are still operated for the purpose of short-term numerical weather forecasting. The resulting data system was originally designed around the following characteristics:

$\bigcirc$ use once and discard

- gross and automated QC

- low accuracy

- meta-data poor

- little involvement of research community

The demands for climate monitoring and forecasting are very different, with climate observing systems approaching data so that they

- keep forever and use many times

o undergo stringent QC

- have high accuracy

o are meta-data rich

- have strong involvement of the research community

A longstanding challenge is to transition our legacy data streams to include the needs of climate applications much work has been done towards this goal already. The corollary is to ensure any new data streams serve both short-term forecasting needs (rapid free data distribution to operational centres) and climate applications (high accuracy) e.g. Argo. Through a dual use system we will ensure maximum the benefit to society.

\section{DISCUSSION}

The global ocean temperature observing system has made impressive progress over the past decade in some areas, such as broadscale observing via Argo and satellite altimetric observations. Monitoring ocean heat advection, the polar, marginal and deep oceans remains inadequate. Some clear next steps emerge from the community deliberations at OceanObs'09, which are outlined above. These can be used as a guide to focus international efforts over the next decade so that future generations have a stronger basis on which to understand, adapt to and predict our climate and environment. 


\section{REFERENCES}

1. Busalacchi, A. (2010). "Celebrating a Decade of Progress and Preparing for the Future: Ocean Information for Research and Application" in these proceedings (Vol. 1), doi:10.5270/OceanObs09.pp.10

2. Donlon, C. \& Co-Authors (2010). "Successes and Challenges for the Modern Sea Surface Temperature Observing System" in these proceedings (Vol. 2), doi:10.5270/OceanObs09.cwp.24.

3. Goni, G. \& Co-Authors (2010). "The Ocean Observing System for Tropical Cyclone Intensification Forecasts and Studies" in these proceedings (Vol. 2), doi:10.5270/OceanObs09.cwp.36.

4. Hoegh-Guldberg, O. (1999). Climate change, coral bleaching and the future of the world's coral reefs. Mar. Frshwtr. Res, 50,839.

5. Behrenfeld, M. J., R. T. O’Malley, D. A. Siegel, C. R. McClain, J. L. Sarmiento, G. C. Feldman, A. J. Milligan, P. G. Falkowski, R. M. Letelier and E. S. Boss (2006). Climate-driven trends in contemporary ocean productivity. Nature, 444, 7120, 752-755.

6. Bryden, H. L. (2000). Ocean Transport of Heat, 2000: In Ocean Circulation and Climate: Observing and Modelling the Global Ocean. Eds. Gerold Siedler, John Church and John Gould, Academic Press, AIP International Geophysics Series, Volume 77, 715 pages, ISBN 0-12-261351-7.

7. Balmaseda, M. \& Co-Authors (2010). "Initialization for Seasonal and Decadal Forecasts" in these proceedings (Vol. 2), doi:10.5270/OceanObs09.cwp.02.

8. Latif, M. \& Co-Authors (2010). "Dynamics of Decadal Climate Variability and Implications for its Prediction" in these proceedings (Vol. 2), doi:10.5270/OceanObs09.cwp.53.

9. Hurrell, J. \& Co-Authors (2010). "Decadal Climate Prediction: Opportunities and Challenges" in these proceedings (Vol. 2), doi:10.5270/OceanObs09.cwp.45.

10. Hansen, J., et al. (2005), Earth's energy imbalance: Confirmation and implications. Science, 308, 14311435, doi:10.1126/science. 1110252 .

11. Cazenave, A. \& Co-Authors (2010). "Sea Level Rise - Regional and Global Trends" in these proceedings (Vol. 1), doi:10.5270/OceanObs09.pp.11.

12. Palmer, M. \& Co-Authors (2010). "Future Observations for Monitoring Global Ocean Heat Content" in these proceedings (Vol. 2), doi:10.5270/OceanObs09.cwp.68.

13. Levitus, S., J. Antonov and T. Boyer, (2005). Warming of the world ocean, $1955-2003$. Geophys. Research Letters, 32, L02604, doi:10.1029/2004GL021592

14. Gouretski, V. V., and K. P. Koltermann, 2007: How much is the ocean really warming? Geophys. Res. Lett., 34, L01610, doi:10.1029/2006GL027834.

15. Freeland, H. \& Co-Authors (2010)."Argo - A Decade of Progress" in these proceedings (Vol. 2), doi:10.5270/OceanObs09.cwp.32.
16. Lyman, J.M. \& Johnson, G.C. (2008). Estimating Annual Global Upper-Ocean Heat Content Anomalies despite Irregular In Situ Ocean Sampling. J. Climate., 21, 56295641 .

17. Wijffels, S.E., J. Willis, C. M. Domingues, P. Barker, N. J. White, A. Gronell, K. Ridgway, J. A. Church (2008). Changing eXpendable Bathythermograph Fall-rates and their Impact on Estimates of Thermosteric Sea Level Rise. J. Climate, 21, 5657-5672.

18. Gronell, A. and S. Wijffels (2008). A Semi-automated Approach for Quality-controlling Large Historical Ocean Temperature Archives, J. Atm. Ocean. Tech., 25, doi:10.1175/JTECHO539.1.

19. Goni, G. \& Co-Authors (2010). "The Ship of Opportunity Program" in these proceedings (Vol. 2), doi:10.5270/OceanObs09.cwp.35.

20. Hood, M. \& Co-Authors (2010). "Ship-Based Repeat Hydrography: A Strategy for a Sustained Global Program." in these proceedings (Vol. 2), doi:10.5270/OceanObs09.cwp.44.

21. Rintoul, S. \& Co-Authors (2010). "Southern Ocean Observing System (SOOS): Rationale and Strategy for Sustained Observations of the Southern Ocean" in these proceedings (Vol. 2), doi:10.5270/OceanObs09.cwp.74.

22. Garzoli, S. \& Co-Authors (2010). "Progressing Towards Global Sustained Deep Ocean Observations" in these proceedings (Vol. 2), doi:10.5270/OceanObs09.cwp.34.

23. Johnson, G. C., S. Mecking, B. M. Sloyan, \& Wijffels. S. E. 2007. Recent bottom water warming in the Pacific Ocean. J. Climate, 20, 5365-5375.

24. Dushaw, B. \& Co-Authors (2010). "A Global Ocean Acoustic Observing Network" in these proceedings (Vol. 2), doi:10.5270/OceanObs09.cwp.25.

25. Levitus, S., R. D. Gelfeld, T. Boyer, and D. Johnson, 1994: Results of the NODC and IOC Oceanographic Data Archaeology and Rescue Projects: report 1. United States, National Environmental Satellite, Data, and Information Service. NODC Key to Oceanographic Records Documentation No. 19, 73, pp.

26. Rayner, N. \& Co-Authors (2010). "Evaluating Climate Variability and Change from Modern and Historical SST Observations" in these proceedings (Vol. 2), doi:10.5270/OceanObs09.cwp.71. 